\title{
Development of a Novel Sensor for Gear Teeth Wear and Damage Detection
}

\author{
Vikram Sridhar and Kam Chana \\ Oxford Thermo-Fluids Institute, University of Oxford, Oxford, OX2 OES, United Kingdom \\ vikram.sridhar@eng.ox.ac.uk \\ kam.chana@eng.ox.ac.uk
}

\begin{abstract}
Health monitoring of mechanical transmission systems is an important area of research. Mechanical transmission systems, especially gear boxes in aircraft, automobiles, and wind turbines etc. account for many of the maintenance costs due to repairs, replacements and downtime. Gear boxes can experience high level of failure due to varied load conditions and harsh environments. Replacing the gear box is quite an expensive process and has significant downtime. Current gear box monitoring involves mainly measuring vibrations, however vibrations occur when the fault in the gear has already progressed significantly. Gear teeth monitoring lacks sensor technology to successfully detect tooth damage and misalignment.
\end{abstract}

This paper presents a new concept gear teeth damage detection using eddy current sensors fitted on to the teeth of an idler gear at various locations. These sensors detect various faults encountered in a gear such as micro and macro pitting of the tooth surface, contact wear etc. Eddy current sensors are already being used to detect turbomachinery blade vibrations and tip clearance as they are robust and immune to contamination. In the present case, we use an idler gear that incorporates miniature eddy current sensors and state of the art electronics with wireless data transmission to enable the device to operate remotely and in harsh environments. A rotating rig with gears (spur and helical) and oil supply was built to test and validate the sensor by seeding various faults on the tooth surface. The results show that the idler sensor gear was able to detect various faults. The new eddy current sensor idler gear concept will enable health monitoring of the gearbox and ensure timely maintenance and reduction in operation costs.

\footnotetext{
$\overline{\text { Vikram Sridhar et }}$ al. This is an open-access article distributed under the terms of the Creative Commons Attribution 3.0 United States License, which permits unrestricted use, distribution, and reproduction in any medium, provided the original author and source are credited.

https://doi.org/10.36001/IJPHM.2021.v12i3.2961
}

\section{INTRODUCTION}

Health monitoring of transmission systems is an active area of research. Transmission systems in wind turbines, rotor aircraft and heavy machinery require timely maintenance to prevent failures (Randall, 2004), (Lu, Li, Wu, \& Yang, 2009) and (Wang, Ismail, \& Golnaraghi, 2001). Currently, the monitoring is done through sensing of abnormal vibrations and acoustic emissions. However, these may not be ideal due to external factors such as wind loads, rotor flutter etc. Failure of a gearbox can be catastrophic and expensive when it comes to aircraft and in the case of off-shore wind turbines, the repair and replacement costs are significant.

Current technology for gearbox monitoring includes measuring external/internal vibration (Watson, Byington, \& Behbahani, 2007), online and offline oil debris, acoustic emissions and temperature. The vibration is measured with the use of accelerometers (Lenski, Spencer, Drago, Valco, \& Oswald, 1993) that are mounted in various locations and the temperature sensors are immersed in the oil. During operation, casing vibrations can indicate gearbox faults by comparing the signal with a baseline over a period of time. However, the faults can be masked due to other noise. The vibrations also occur when the wear has reached a significant level. Also, these sensors cannot detect wear such as micro and macro-pitting of the gear teeth as these may not cause the level of vibrations detected by the sensors. A similar issue is also faced by oil debris monitoring sensors where the gears would have reached the point of imminent failure in order to be detected by the debris in oil samples. Acoustic Emission sensor also has a similar limitation where the signals originate when a crack is initiated which is quite late for preventive maintenance.

Gearbox failure modes are mainly caused by surface wear and fatigue. These different failure modes depend on both the gearbox speed and load level. Wear is caused due to the friction between the two meshed gear faces and the high stresses in the contact area between the teeth. Poor lubrication can accelerate the accumulation of wear and these can lead to 
surface defects such as scuffing, galling, micro-pitting and macro-pitting, brinelling and spalling (Liu \& Pines, 2002). Fatigue is caused by repeated cycling of loads that are within the elastic limit of the material, but causes progressive damage to a localised area of the gear tooth experiencing the greatest strain. Fatigue failure occurs in three stages; crack initiation, propagation and finally complete fracture. In addition to wear and fatigue, excessive forces can cause plastic deformation and/or catastrophic fracture of gearbox components, for example the shearing of gear teeth. These excessive forces can be due to misalignment, vibrations in the shaft and unexpected loads or overload.

A new concept using miniature eddy current sensor has been developed to monitor the wear of gear teeth in real time. This approach is suited for gearbox monitoring due to its immunity to contamination from oil, dust and other non metallic components. This paper focuses on the advancement of the preliminary work done earlier (Chana, Cardwell, \& Sullivan, 2013) to next technology readiness level by improving the sensor design, incorporation of on board electronics with wireless transmission, resistance to harsh environments and processing of the signals in real-time. The study also expands the concept to spur and helical gears with various seeded faults such as pitting, groove and slot on various teeth of a metallic gear.

\section{EDDY CURRENT SENSOR}

Eddy current sensors are extensively used in proximity, displacement and tip timing applications as it is quite robust, immune to contamination and shown to be accurate for the application (Chana \& Cardwell, 2008), (Sridhar \& Chana, 2017). There are two forms of eddy current sensors: passive and active. The passive uses a permanent magnet to generate the field and the active uses high frequency AC to generate an oscillating field. When a conducting material passes the sensor, the magnetic field interacts with the material, and eddy currents are generated in the material which generate their own magnetic field and opposes the primary field generated by the sensor, leading to a change in sensing coil voltage that is used to measure the effect of the eddy currents.

The eddy currents are strongest near the surface of the material, and decreases in an exponential way as you move away from the surface. The strength of eddy currents is dependent on the material and distance. The penetration depth is given by the equation.

$$
\delta \approx \frac{661}{\sqrt{f \mu_{r} \sigma}}
$$

where $\delta=$ Depth (mm), $f=$ Frequency $(\mathrm{Hz}), \mu_{r}=$ Relative Magnetic Permeability (Dimensionless) and $\sigma=$ Electrical conductivity (\%IACS).

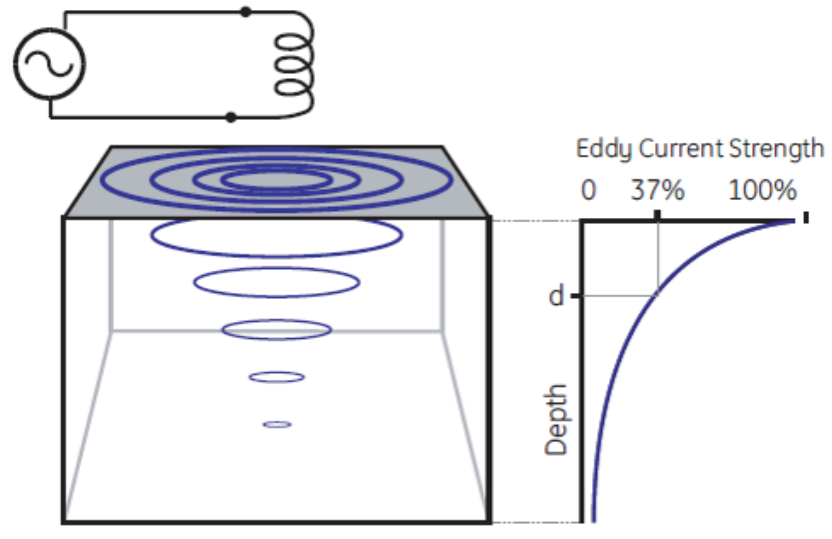

Figure 1. Sensor range with depth

In their application to damage detection, a defect in or below the surface of the material presents a discontinuity in the conduction path, thereby disrupting the flow of eddy currents in the material, and altering their effect on the primary field and sensing coil. The depth to which defects can be detected depends on the depth of penetration of the induced eddy currents into the material (figure 1). Therefore, varying the driving frequency of the electric coil generating the primary magnetic field can be used to control the depth to which the material (for example, a gear tooth), can be monitored.

\section{IDLER GEAR WITH EDDY CURRENT SENSORS}

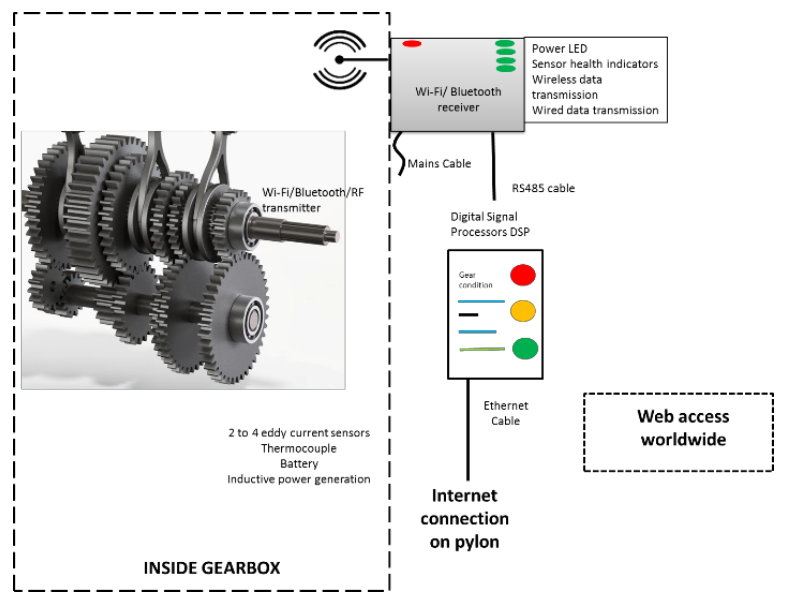

Figure 2. System architecture

Figure 2 shows the system architecture for a gearbox health monitoring. The system architecture firstly has to address the need to drive the eddy current sensor in the idle gear teeth and hence in rotation. The sensor requires a resonant circuit and a demodulator which has to be either on the body of the gear or the shaft. The signal from the resonant circuit has to be transmitted from the rotating frame to the stationary frame with good signal to noise ratio. Digitizing the signal in the rotating 
frame and transmitting a digital signal would be the best solution from the signal to noise ratio perspective but will require increased power in the rotating frame. The rotating electronics have to be powered which can be done in two ways: If a battery alone is used, the life requirements are 3 years which is the expected life of the gearbox in a wind turbine and can vary depending on the application. However, if this is not possible then on-board generation would be required using a coil-magnet arrangement to trickle charge the battery, making the system more complex and more challenging. The signal from the idler gear can be transmitted in digital form to an on-board monitoring system for real-time monitoring.

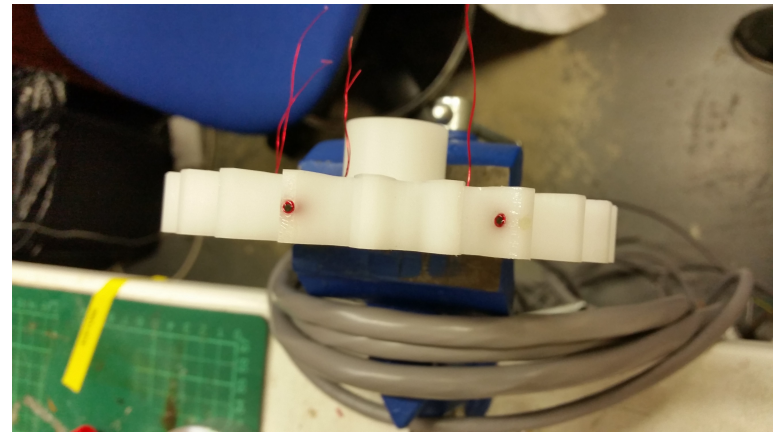

(a) Eddy current sensor in the idler gear

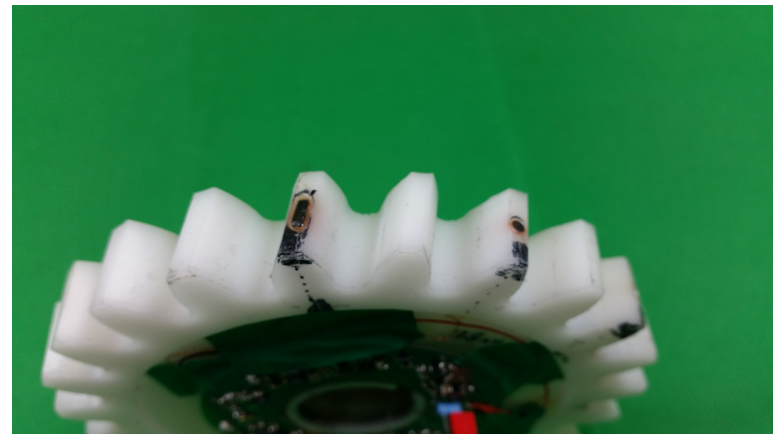

(b) Shaped eddy current sensor for helical

Figure 3. Eddy current sensor in idler gear

An idler gear sensor was built out of Delrin ${ }^{\circledR}$ and had 23 teeth as shown in figure 3 . The idler gear is being driven by the metallic gear that is to be monitored and this had 24 teeth. Having $\mathrm{n}-1$ teeth on the idler gear gave sequential monitoring of the teeth on the driver gear every revolution. There is no loading on the idler gear as this can damage the gear and the electronics. Three eddy current sensors were incorporated into the idler spur gear (figure 3a) and four in idler helical gear (figure $3 b$ ). One was at the top face of the tooth for detecting defects in the root of driver gear and the second on the pressure face for detecting damages on the tooth face. The eddy current sensors were wound 40-60 turns using a $0.1 \mathrm{~mm}$ polyurethane coated wire on a ferrite core of $1.5 \mathrm{~mm}$ diameter to give high inductance and $\mathrm{Q}$ factor for a small diameter. The inductance for these sensors varied between $12-15 \mu \mathrm{H}$. The

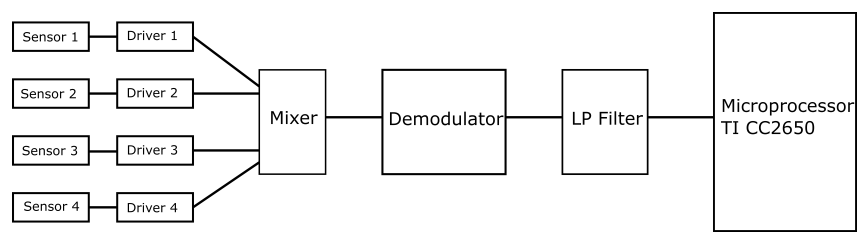

(a) Block diagram of the electronics

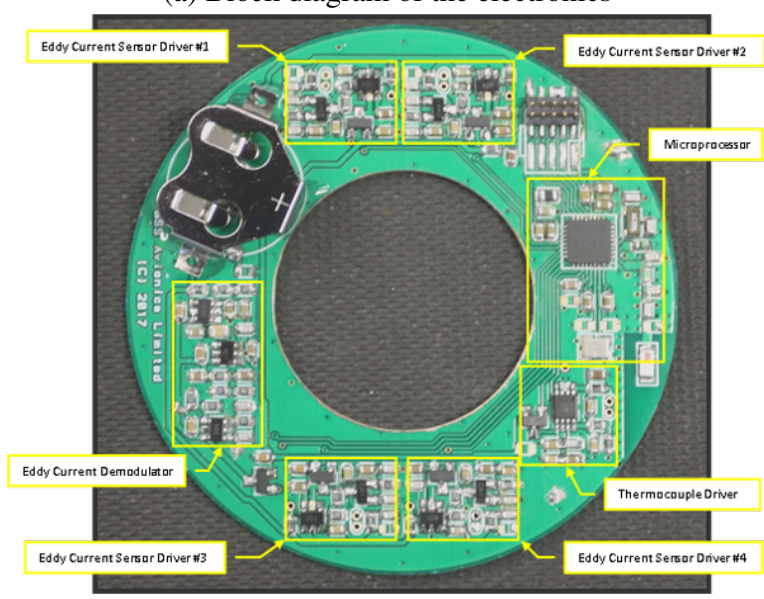

(b) Electronics

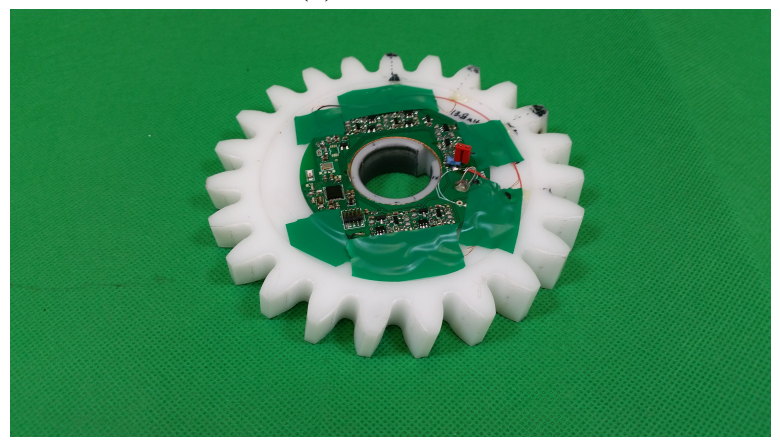

(c) Board on idler gear

Figure 4. Idler gear electronics

fourth sensor on the helical gear was oval shaped to cover a larger part of the tooth.

The electronics for driving the sensor and sending the data wirelessly via bluetooth was incorporated onto a circular board that went on the idler gear. The board also incorporates provision for a button cell battery for power and provision for mounting batteries on the other side of the idler gear. The board is capable of driving four eddy current sensors and a thermocouple. The board has a 9 DOF sensor, however, these were not used in the present tests.

The block diagram for the electronics is as shown in figure 4a. Each sensor driver consists of a colpitts oscillator (Colpitts, 1918). The modulated signal is passed through a mixer, demodulator, low pass filter and then to a microprocessor. The oscillator is configured to produce a sine wave with a center frequency that is between $1 \mathrm{MHz}$ and $4 \mathrm{MHz}$ and with a "free 
air" amplitude of around $1 \mathrm{~V}$ peak to peak. The frequency of oscillation is determined by the capacitance $\mathrm{C}$, together with the inductance of the sensor (L) according to the following equation:

$$
f=\frac{1}{2 \pi \sqrt{L C}}
$$

The output from the sensor driver is a high frequency carrier $(2.5 \mathrm{MHz} 1 \mathrm{Vpp})$ sine wave amplitude modulated by a much lower frequency (and amplitude) signal which is the signal that must be recovered. If the idler wheel is spinning at $3000 \mathrm{RPM}$ or $50 \mathrm{~Hz}$, then $50 \mathrm{~Hz}$ will be the primary frequency of interest, but the detail in the signal will extend to much higher frequencies (perhaps 50 times higher $-2500 \mathrm{~Hz}$ ). If the sensor comes into very close proximity with the gear wheel, then modulation depth can be as much as $50 \%$, but will typically be less than $10 \%$. The output from the RMS demodulator still contains significant carrier frequency content because the filter in the demodulator is effectively only first order. At $1 \mathrm{MHz}$ the carrier attenuation is around $-30 \mathrm{~dB}$, and at $5 \mathrm{MHz}$ it is around $-48 \mathrm{~dB}$. Additional low pass filtering is required for the following reasons: Firstly, the low pass filter filters the input to remove the high frequency carrier, but pass as much of the modulated signal as possible. The design in the prototype when the RMS filter is taken into account is effectively a $4^{\text {th }}$ order $(24 \mathrm{~dB} /$ octave) circuit, and component values have been chosen to remove as much carrier whilst retaining as much detail in the signal as possible. Secondly, the low pass filter needs to filter the input to the ADC (in the microprocessor) such that Nyquist sampling and aliasing errors are avoided. In brief, the filter should remove any frequency components higher than half the sampling frequency. In practice, since the filter cannot be 'Brick Wall sharp' in its response, the filter needs to start rolling off at around $1 / 4$ the sample rate. The ideal sampling frequency is application dependent and therefore not currently known, so for the prototype the low pass filter response was chosen to be a $4^{\text {th }}$ order Butterworth filter with $-3 \mathrm{~dB}$ at $18 \mathrm{kHz}$, and a pass band gain of $1(+0 \mathrm{~dB})$.

In the current application, a Texas Instruments ${ }^{\circledR} \mathrm{CC} 2650 \mathrm{mi}-$ croprocessor was used (Texas Instruments, 2016) to control the sensors, process data and transmit. This contains a user programmable $\mathrm{ARM}^{\circledR} \mathrm{M} 3$ processor, a separate sensor controller processor used to handle the sensor interface and a hard coded ARM M0 processor to handle the Bluetooth communications. Whilst not quite a single chip solution, it does dramatically cut down the number of components required to around 20. Operating current is around $7 \mathrm{~mA}$ (when transmitting) dropping to $1 \mu A$ when in standby. The integrated Bluetooth interface is connected directly to a specially designed Balun - a Johansson Technology ${ }^{\circledR}$ 2450BM14G0011. This device has been specifically designed to match the RF output characteristics of the TI CC2650 processor to an antenna. The antenna used in this design is a chip type also produced by a Johansson Technology - an LT2450AT18A100. All the daq was done on-board by a Texas Instruments microcontroller and then transmitted. To conserve power, each of these units was individually powered up or down so that typically only one is enabled at any time. The signal demodulator is common to all sensor drivers, and can also be powered down when not in use. The microprocessor also contains embedded battery voltage and chip temperature sensors. The board is a double-sided $0.8 \mathrm{~mm}$ thick PCB with a $65 \mathrm{~mm}$ outside diameter and a $40 \mathrm{~mm}$ diameter hole in the middle (figure $4 \mathrm{~b}$ ). All components are surface mounted on the topside. When fully populated, the assembly as shown is $5 \mathrm{~mm}$ thick and Electrolube ${ }^{\circledR}$ URC200D conformal coating of $25 \mu \mathrm{m}$ thick was used to make the electronics oil proof (figure 4c). Two lithium batteries are used to power the electronics and sensors. The size of the battery was chosen and mounted on the other side of the gear such that they last for over 3 years. The batteries were mounted diametrically opposite to each other to keep the gear in balance. The electronics is generally in standby mode and will take measurements at specified time intervals for 1000 revolutions initially and as the fault progresses, it will take the data more often.

\section{EXPERIMENTAL SETUP}

The experimental setup consists of a rig with two shafts: one for the driver and another for idler gear (driven). The shafts were mounted on pillow block bearings and they can be moved laterally to test different alignments of the gears. The gears were meshed and aligned such that there were no axial or radial offsets. The driver gear has 24 teeth and the idler gear has 23 teeth. The gears were spun at a constant speed of 1000 RPM using a standard variable speed motor for all the test cases. The data was sampled at $1 \mathrm{kHz}$ and was found to be sufficient to capture the imperfections at the speeds that were tested. Both, spur and helical gears were used in the tests as these cover more than 90 percent of the gear boxes.

Each driver gear was seeded with faults as described below. The faults were put on different tooth so that we can get a clear picture of the signal for further analysis. However, we haven't considered gear misalignments (axial, radial, pitch, yaw), improper meshing and high temperature operating environment due to the use of lithium batteries.

- Single shallow transverse groove across the root of the tooth ( $15 \mathrm{~mm}$ long $\times 2 \mathrm{~mm}$ wide $\mathrm{x} 0.5 \mathrm{~mm}$ deep)

- Single deep transverse slot across the mid-point of the tooth face ( $15 \mathrm{~mm}$ long $\mathrm{x} 2 \mathrm{~mm}$ wide $\mathrm{x} 2 \mathrm{~mm}$ deep)

- Single punch dot on one side of the tooth face $(0.5 \mathrm{~mm}$ dia $\times 0.5 \mathrm{~mm}$ deep) 

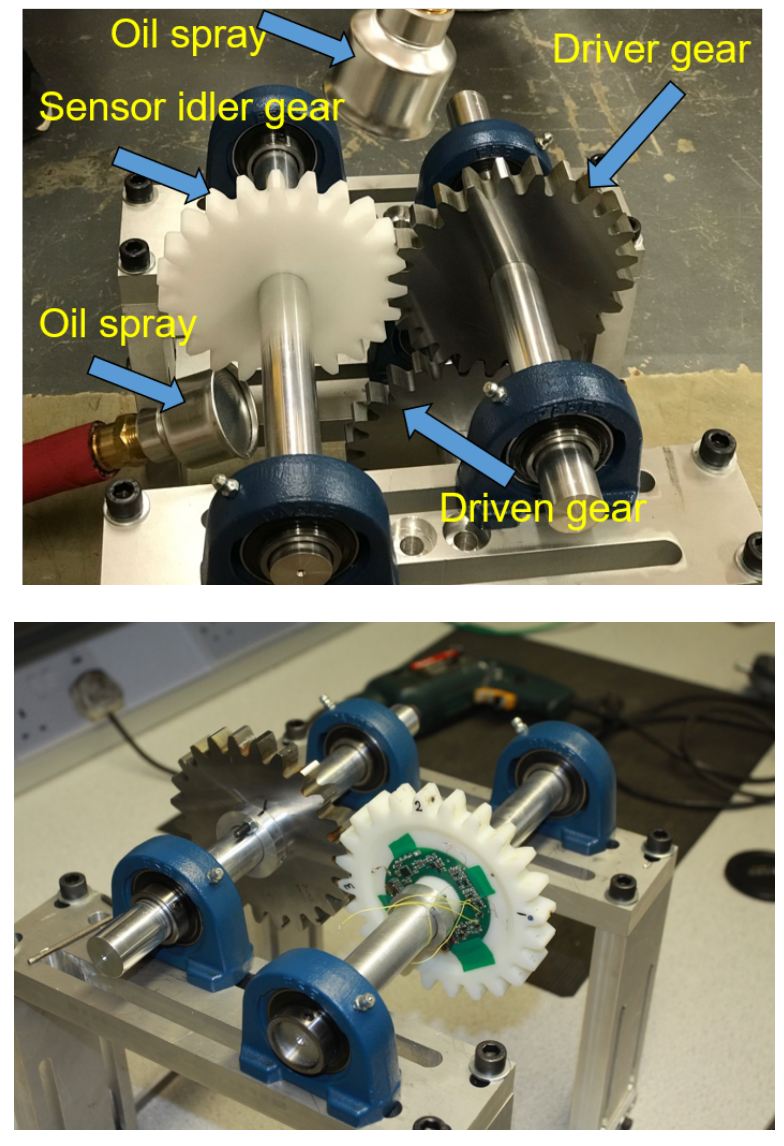

Figure 5. Experimental setup

\section{RESUltS AND DisCUSSION}

Results are presented for both spur and helical gears with various seeded faults as mentioned in the previous section.

\subsection{Spur gear}

The first phase of testing comprised of using spur gears with various seeded faults. Figures 6 to 8 shows the various seeded faults and signal comparison with a normal tooth. The peak of the curve is where the sensor is closest to the metal tooth as this causes the highest modulation of the carrier signal. In all three cases, the amplitude of the signal changes with the size of the fault when compared to a normal tooth as anticipated. These lower level of signal amplitudes occur on different regions of the curve due to the way the teeth mesh together and the position of the sensor when it sees the faults. The values extracted from the difference between the peaks of tooth with and without fault for various cases is found to be $50(14 \%)$, $30(2 \%)$, and $75(11 \%)$ for dot, groove and slot respectively. The ADC difference value for the dot is much higher than the groove as the groove is in the valley and the dot is on the face. When the tooth engages, the sensor on the tooth face of the idler gear is closer to the fault on the tooth face of the

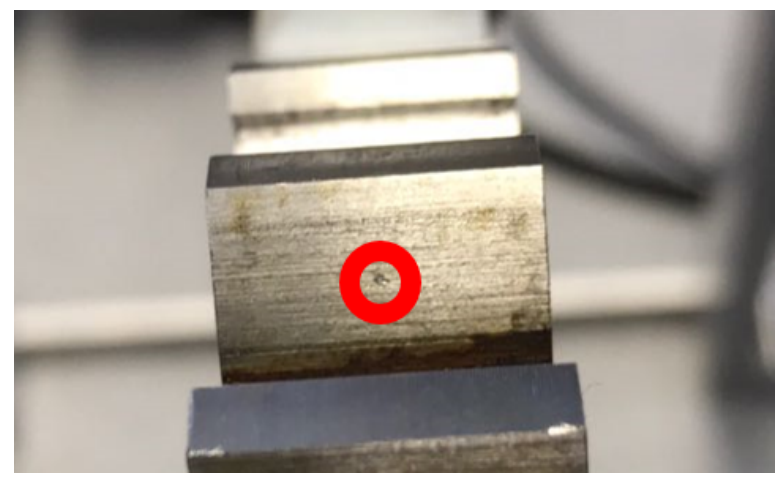

(a) Spur gear with a dot

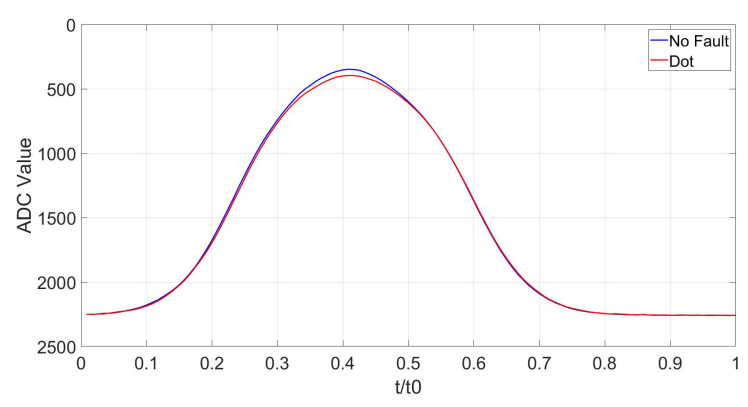

(b) Signal comparison from sensor

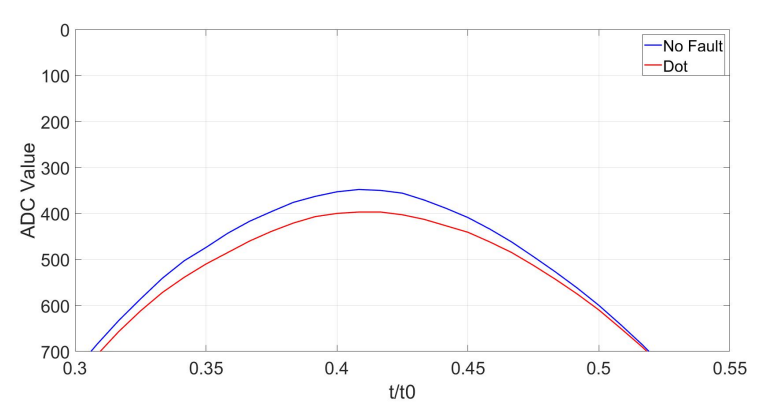

(c) Zoomed view of the peak

Figure 6. Pitting on face of the gear

faulty gear, whereas, when the fault is in the valley, the sensor mounted on top tooth face of the idler gear is much farther than the fault and this reduces the signal strength. It should also be noted that the modulation values are different for each case, which is due to the variation in sensor inductance and the distance of the sensor from the defect.

\subsection{Helical gear}

The next phase of the programme was to test the sensors on helical gears. Again a 24 teeth helical gear was used and seeded with faults. A 23 teeth idler helical gear was instrumented with four eddy current sensors with one of them designed with an elongated coil to increase the detected area. Figures 10 to 11 show the various seeded faults and the signal. Notably, a similar variation in the signal levels is seen with helical gears and the elongated coil detects the fault for 


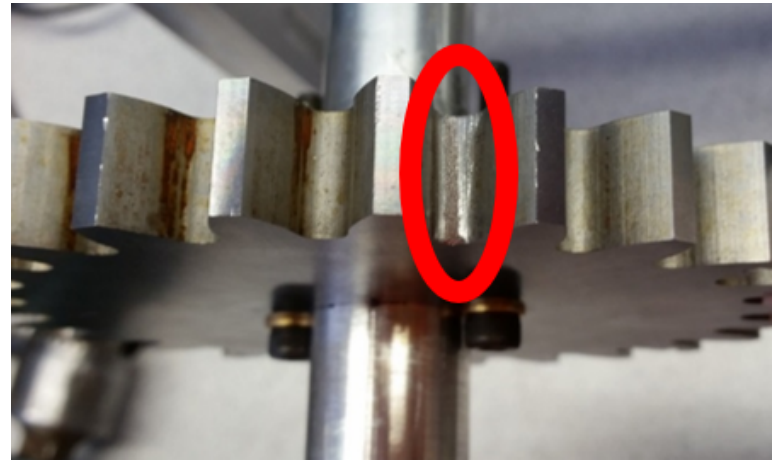

(a) Shallow groove in the valley

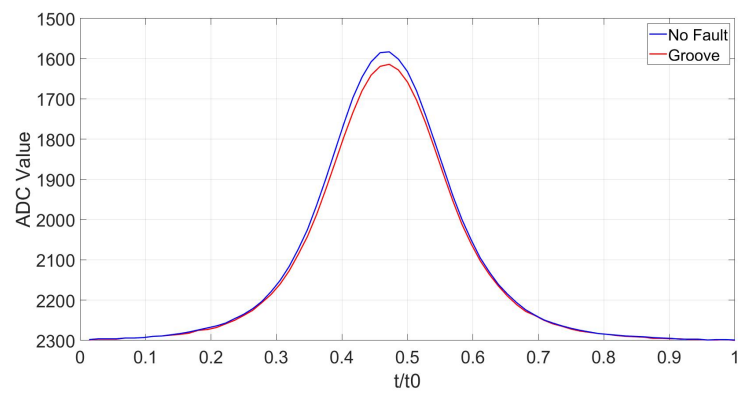

(b) Signal comparison from sensor

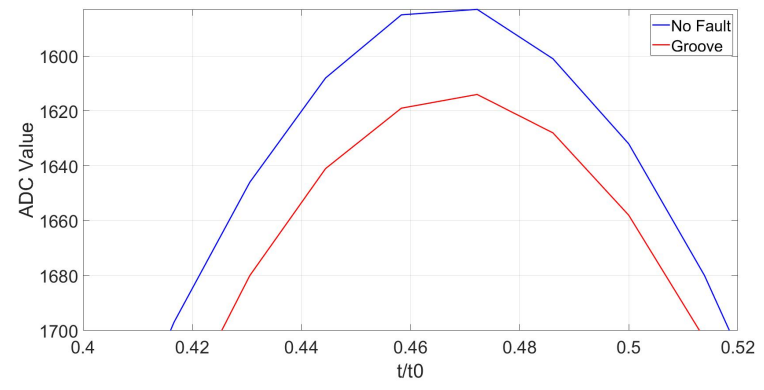

(c) Zoomed view of the peak

Figure 7. Groove on the gear

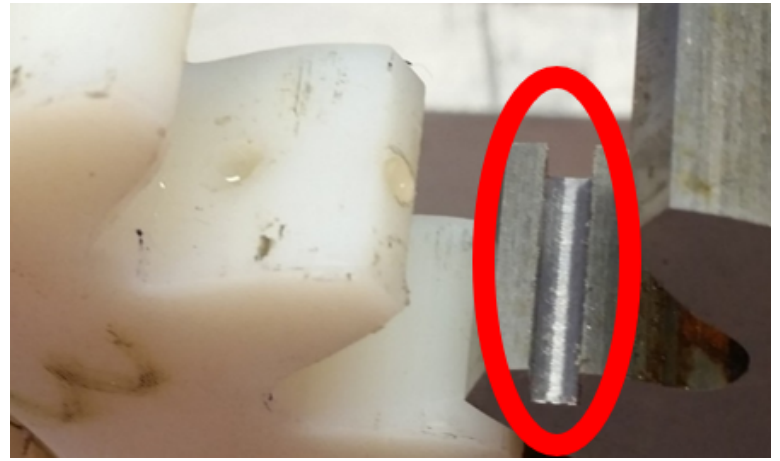

(a) Deep slot on the tooth face

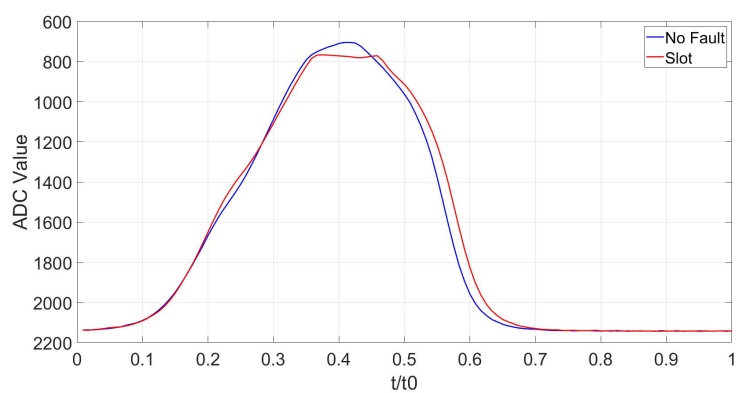

(b) Signal comparison from sensor

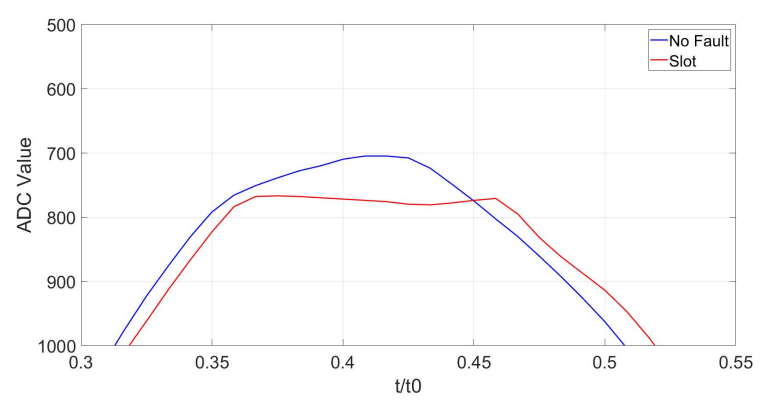

(c) Zoomed view of the peak

Figure 8. Deep slot on the gear 


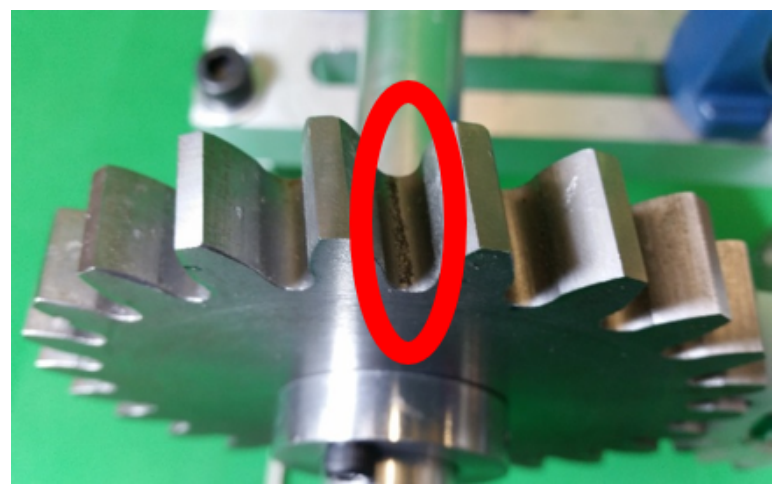

(a) Groove in the root

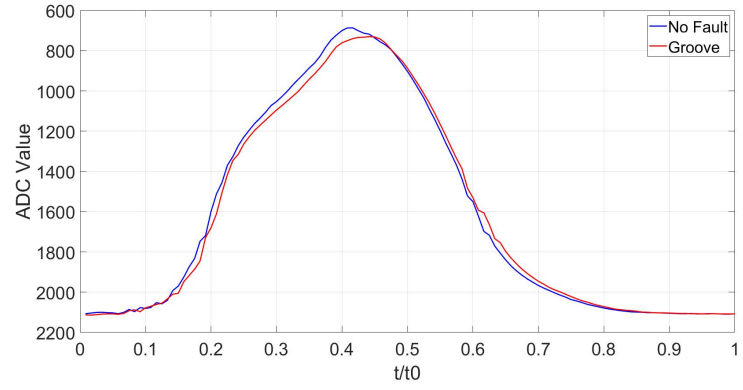

(b) Signal comparison from sensor

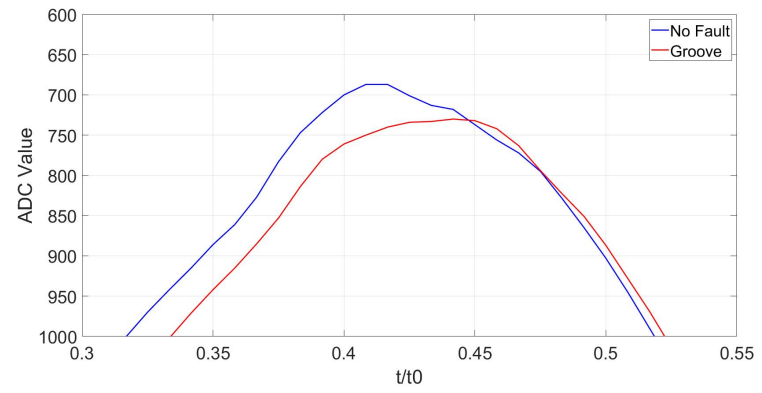

(c) Zoomed view of the peak

Figure 9. Groove on the gear

a much longer area than the cylindrical sensor. The difference in the ADC peak values with and without faults is found to be $63(9 \%), 303$ (44\%), 47 (4\%) for groove in the root, slot on the face for cylindrical sensors and slot in the valley with shaped eddy current sensor respectively. The shaped eddy current is much more sensitive as it can pick up the fault over its entire length compared to the cylindrical sensors. Both these tests demonstrate that the sensor is able to pick-up various faults on the gears.

\section{Conclusions}

A new technique for monitoring gearboxes in real-time has been demonstrated and validated by developing electronics that were installed on to an idler gear that meshes with the power transmitting gear being monitored. A test rig was built and used to validate the sensors, rotating gear electronics, sta-

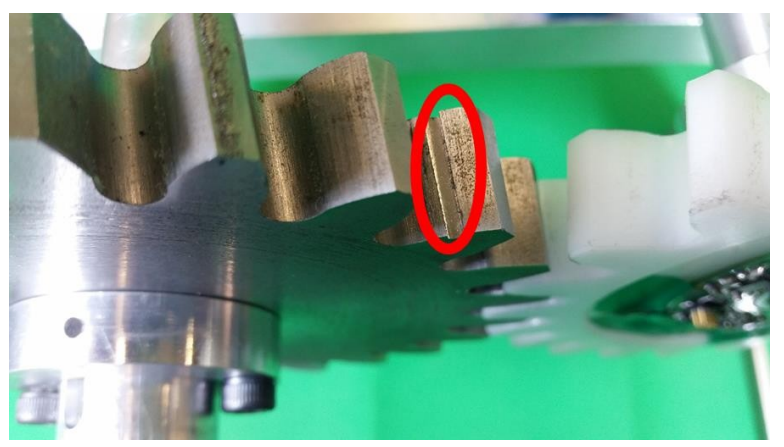

(a) Deep slot on the tooth face

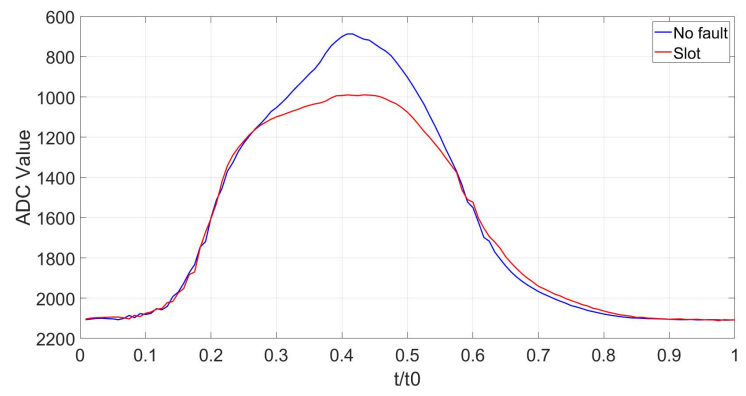

(b) Signal comparison from sensor

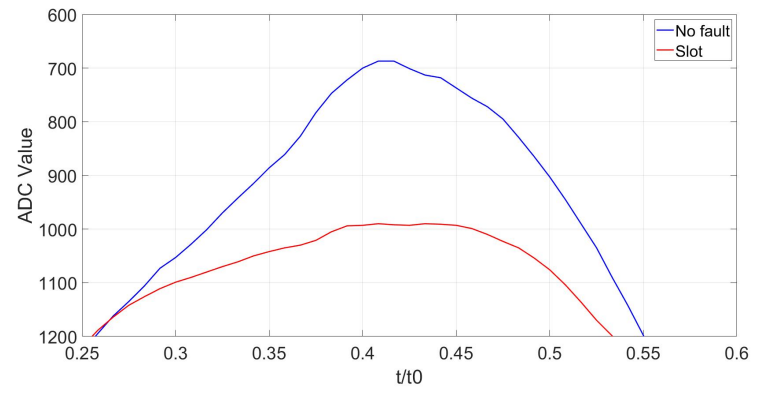

(c) Zoomed view of the peak

Figure 10. Slot on the gear

tionary Bluetooth receiver electronics, data collection via a laptop computer and a dash-board to display the results for fault detection. The sensor system was shown to detect various types of faults such as micro-pitting, shallow grooves and major faults such as slots. This was demonstrated on both spur and helical gears which are generally used in gearboxes. The results show that the idler gear concept can be incorporated into a gearbox for real time monitoring.

\section{ACKNOWLEDGEMENT}

The authors would like to acknowledge Innovate UK for funding the project, Malcolm Robb from GSS avionics ltd for design and manufacture of electronics, Sunny Chana for his help during experiments and Prab Birdi for his help in design of the rig. 


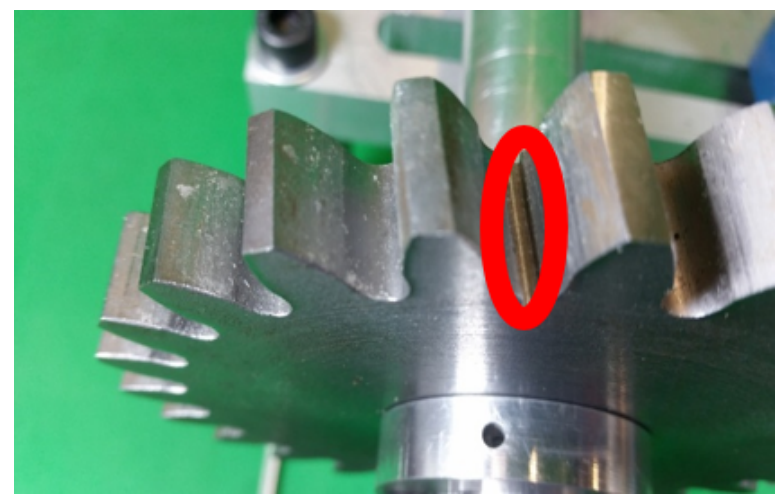

(a) Deep slot in the root

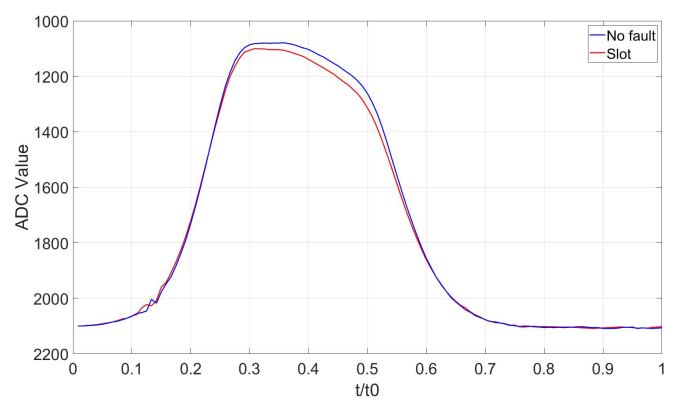

(b) Signal comparison from sensor

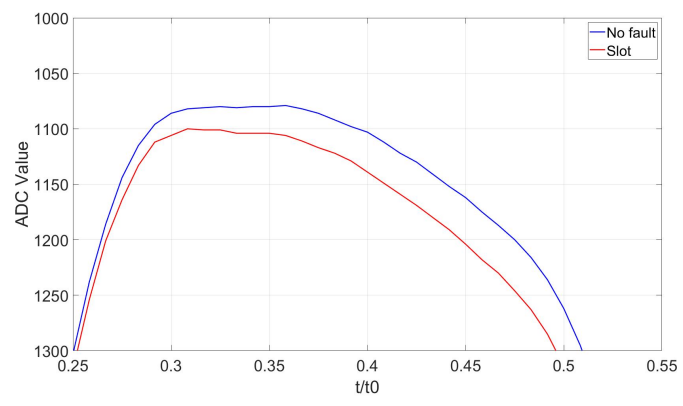

(c) Zoomed view of the peak

Figure 11. Slot on the gear with shaped eddy current sensor

\section{REFERENCES}

Chana, K. S., \& Cardwell, D. N. (2008). The use of eddy current sensor based blade tip timing for fod detection. In Proceeding of the ASME Turbo Expo 2008: Power for Land, Sea and Air. Berlin, Germany.

Chana, K. S., Cardwell, M. T., \& Sullivan, J. S. (2013). The development of a new concept for gear teeth wear anddamage detection. In Proceedings of ASME Turbo Expo 2013 Turbine Technical Conference and Exposition. San Antonio, Texas, USA.

Colpitts, E. H. (1918). Oscillation generator (No. US1624537).

Lenski, J. W. J., Spencer, R. H., Drago, R. J., Valco, M. J., \& Oswald, F. B. (1993). Gear sound levels with various tooth contact ratios and forms (Tech. Rep. No.
106432). Adelphi, Maryland: NASA.

Liu, L., \& Pines, D. (2002). The influence of gear design parameters on gear tooth damage detection. ASME Journal of Mechanical Design, 124(4), 794-804.

Lu, B., Li, Y., Wu, X., \& Yang, Z. (2009). A review of recent advances in wind turbine condition monitoring and fault diagnosis. In IEEE Power Electronics and Machines in Wind Applications. Lincoln, Nebraska.

Randall, R. B. (2004). State of the art in monitoring rotating machinery part 1. Sound and Vibration, 38(3), 14-21.

Sridhar, V., \& Chana, K. (2017). Development of a combined eddy current and pressure sensor for gast turbine blade health monitoring. In Proceedings of ASME Turbo Expo. Charlotte, North Carolina, USA.

Texas Instruments. (2016). CC2650 simplelink multistandard wireless MCU.

Wang, F., Ismail, F., \& Golnaraghi, M. (2001). Assessment of gear damage monitoring techniques using vibration measurements. Mechanical Systems and Signal Processing, 15(5), 905-922.

Watson, M. J., Byington, C. S., \& Behbahani, A. (2007). Very high frequency monitoring system for engine gearbox and generator health management. In SAE Technical Paper.

\section{BIOGRAPHIES}

Vikram Sridhar is a Post-Doc at the Oxford Thermo-Fluids Institute, University of Oxford. He completed his undergraduate degree in Mechanical engineering in India and worked for 3 years. He later completed his PhD in Aerospace Engineering at the University of New South Wales, Australia focussing on unsteady supersonic aerodynamics. At Oxford he has been working on various projects for over 5 years focusing on unsteady heat transfer and aerodynamics, development of sensors and algorithms for oil condition monitoring, blade tip-timing and tip clearance, cancer detection and fake drugs. He has published over 18 peer reviewed papers, filed 6 patents and licensed 3 software applications to companies.

Kam Chana joined the Oxford Thermo-Fluids Institute in 2010 following 22 years at the MoD and QinetiQ where he held the position Head of Instrumentation and Experimental Programmes and was a QinetiQ Fellow. He held a visiting fellow position at Warwick and Surrey University for over 20 years. He has also held the position as scientific director of the European Virtual Institute for Gas Turbine Instrumentation (EVI-GTI) for 5 years. At Oxford he leads the activities of the Oxford Turbine Research Facility and novel instrumentation for harsh environments. His research areas are in Heat transfer, cooling systems, and development of sensors for blade tip timing and tip clearance, oil contamination and conditioning, and cancer and fake drug detection. He has over 100 peer reviewed published articles and several patents. 